\title{
Identifying Characteristics of Adults Absent from a Metabolic Syndrome Checkup in Japan Using CHAID Dendrograms and Insurance Claim Data
}

\author{
Takashi Naruse, Rumiko Tsuchiya, Natsuki Yamamoto, Satoko Nagata \\ Department of Community Health Nursing, Graduate School of Medicine, University of Tokyo, Tokyo, Japan \\ Email: takanaruse-tky@umin.ac.jp
}

Received 7 August 2015; accepted 28 December 2015; published 31 December 2015

Copyright (C) 2015 by authors and Scientific Research Publishing Inc.

This work is licensed under the Creative Commons Attribution International License (CC BY). http://creativecommons.org/licenses/by/4.0/

(c) (i) Open Access

\begin{abstract}
To prevent the development of metabolic syndrome among adult members of the community, improving the participation rate in the specific medical checkup (a medical examination focused on factors associated with metabolic syndrome prior to the onset of lifestyle-related disease) is an important public health issue. This study used claim data and health checkup data and aimed to detect those community-dwelling adults who were least likely to participate in the specific medical checkup. Analysis included the medical and health checkup chart data of 61,753 adults aged 60 69 years (as of April 2011) who lived in Fukui prefecture, Japan. The chi-squared interaction was used to analyze data. If a person did not participate in the specific medical checkup, individual was categorized as "absent." Between April 2012 and March 2013, 66.3\% of subjects were absent from the specific medical checkup. Those most likely to be absent included those who were also absent at the previous year's checkup, those who were men, and those who did not have an examination for hypertension; 87.9\% of patients who met all of these criteria were absent. Among women who were absent at the previous year's checkup, the absentee rate differed by about $10.0 \%$ between those whose municipalities did $(74.8 \%)$ or did not $(84.2 \%)$ have a free checkup program. Our findings may help public health professionals detect those who require intervention and to effectively and efficiently improve participation in the specific medical checkup.
\end{abstract}

\section{Keywords}

Health Checkup, Adults, Metabolic Syndrome

How to cite this paper: Naruse, T., Tsuchiya, R., Yamamoto, N. and Nagata, S. (2015) Identifying Characteristics of Adults Absent from a Metabolic Syndrome Checkup in Japan Using CHAID Dendrograms and Insurance Claim Data. Health, 7, 1841-1846. http://dx.doi.org/10.4236/health.2015.714202 


\section{Introduction}

The metabolic syndrome is a worldwide problem [1] [2]. In Japan, among those 40 - 74 years of age, 50\% of men and $20 \%$ of women were strongly suspected to have either the metabolic syndrome or the prodromal metabolic syndrome [2]. To improve treatment of the metabolic syndrome, the Ministry of Health, Labor and Welfare in Japan has been promoting the "National Health Promotion Movement in the 21st Century (Health Japan 21)” since 2000 [3]. Since April 2008, the Ministry has required health care insurance providers to provide health checkups to their insured customers between the ages of 40 - 74 [3]. The "specific health checkup" is a medical examination focused on factors associated with metabolic syndrome prior to the onset of lifestyle-related disease. Insurance providers have a mandate to provide a specific health checkup, as well as intensive health education programs for checkup participants deemed to be at high risk for metabolic syndrome. Because it may encourage participants to become aware of their own health problems [4] [5], participation in the heath checkup is an important behavior for improving a healthy lifestyle. The most common insurance provider in Japan is the National Health Insurance, which enrolls over 30\% of the Japanese population [6]. The insurance is managed by each municipality. While the checkups have been rated as favorable, the participation rate is quite low. Eligible adults can receive the checkup once per year (April through March); however, among those enrolled in the National Health Insurance in 2012, only 33.7\% reportedly participate in the annual checkup [7]. The Ministry of Health, Labor and Welfare in Japan has recommended that each municipality achieves a participation rate of $70.0 \%$ by 2017 [8]. To prevent the development of metabolic syndrome among adult members of the community, improving the participation rate in the specific medical checkup is an important public health issue.

Municipal public health professionals, including public health nurses, have a mandate to conduct long-range planning based on needs assessments and to identify the unmet needs of the population [9]. In Health Japan 21, municipalities were required to analyze health insurance claim data to improve understanding and to help with the development of an effective intervention strategy [10]. Knowledge of the characteristics of adults who are typically absent from the specific medical checkup may help to detect a high-risk population and develop an intervention strategy. A large body of research describes factors that predict adult absenteeism from various medical or health checkups [11] [12]. However, the previous studies included variables that cannot be obtained from public data, only from direct surveys for adults. If we can detect those community-dwelling adults who are most likely to be absent from the specific medical checkup using only objective and publically available variables, the information will be beneficial for public health practice.

\section{Methods}

This study was conducted as part of a joint research project between the Institute of Gerontology, the University of Tokyo, and Fukui Prefecture (the Fukui Gerontology Study). The Ethics Committee of the Graduate School of Medicine at the University of Tokyo approved this study. Data used for this research included claim data from National Health Insurance data as well as data from individual medical checkups in the National Health Insurance system. We received written consent to use National Health Insurance data for this research from the Fukui Prefecture National Health Insurance Federation. This Federation insures all 17 municipalities in Fukui prefecture and is responsible for these data. Insured individuals were informed of the research plan through a public relations paper issued by Fukui prefecture.

Because two types of claim data were managed with a common ID for each individual, we were able to identify and merge the same individuals. Information was collected for the period between April 2011 and March 2013 and included medical care insurance service consumption volume, disability level, disease code, region for each month, and whether an individual was absent from the specific medical checkup. All data were provided in the form of anonymous electronic data. We evaluated the medical and health checkup chart data of 61,753 disabled persons aged 60 - 69 years who lived in Fukui Prefecture, Japan and whose data were available for the observation period of April 2011 to March 2013.

\subsection{Measures}

Data regarding participation in the specific medical checkup between April 2012 and March 2013 were obtained (participated $=1$, did not participate $=0$ ). 


\subsection{Individual Variables}

The individual variables examined included age, sex, medical examination history of diabetes mellitus and hypertension, and past participation in the specific medical checkup. Age was obtained from April 2012 claim data. Medical examination history was gathered from receipt data between April 2011 and March 2012. If one or more corresponding codes for diabetes mellitus (E10-14) and hypertension (I10-15) were detected between April 2011 and March 2012, the person was considered to have undergone an examination (examined = 1, not examined $=0$ ) for either diabetes mellitus or hypertension. Past participation in the specific medical checkup was gathered from receipt data between April 2011 and March 2012 (participated = 1, did not participate =0).

\subsection{Municipality Variable}

The existence of free checkup programs was included as municipality variable. This information was obtained from Fukui-prefecture staff.

\subsection{Statistical Analysis}

The research questions were addressed using chi-squared automatic interaction detection (CHAID) technique analysis, a non-parametric analysis based on statistically recursive partitioning algorithms. The CHAID technique has traditionally been used in business and marketing research [13] and public health research [14]. The CHAID technique determines the relative importance of each independent (predictor) variable in explaining group membership in a categorical dependent (outcome) variable. The technique has two steps. In the first, the independent variables are stratified into alternative ordinal groupings to ensure similar percentage distributions of the dependent variable among these categories. Groups may be formed by any possible combination of the levels of an independent variable or by placing cut points at any value of a continuous predictor. In the second step, the technique uses $\mathrm{X}^{2}$ significance levels to determine which independent variable explains the most variance in the dependent variable. The process is repeated for all significant predictor variables until no further significant $\mathrm{X}^{2}$ values are obtained.

Dendrograms are used to display the relative importance of significant independent variables for the dependent variable. The hierarchical nature of the CHAID dendrograms provides a visual depiction of criterion and predictor variable interactions that might not be detected in traditional analytic procedures. The variable at the highest level of the tree is considered to have the closest statistical association with the dependent variable.

In the current analysis, groups were split until the following criteria were reached: tree depth was limited to three levels, no group smaller than 100 was split, no group smaller than 50 was formed, and the alpha level for all statistical tests was 0.05 , corrected for the number of statistical tests within each predictor, using a correction factor analogous to the Bonferroni technique. SPSS ver. 23 and Decision Tree ver. 23 were used for the CHAID analysis.

Of a total of 61,753 subjects, 30,846 were randomly selected as the learning sample for developing the tree model. CHAID was implemented for this learning sample data. After development of the CHAID tree model, we separated the remaining 30,907 subjects by referring the tree model. The prevalence of absent subjects in each node of the tree model was compared between the learning sample and the remaining testing sample. If the two samples showed the same trend in the prevalence of absenteeism, the model was considered reliable.

\section{Results}

Subject characteristics are shown in Table 1. About $46.4 \%$ of subjects were male, and the average age was 64.8 years. Between April 2011 and March 2012, 5,130 subjects (8.3\%) had undergone a medical examination for diabetes mellitus, 15,092 (24.4\%) had undergone one for hypertension, and 20,831 (33.7\%) participated in the specific medical checkups. Only $2.2 \%$ lived in a residence with a subsidy for the specific medical checkup.

Figure 1 illustrates the relative importance of the significant independent variables in determining absenteeism from the specific medical checkup in 2012. Of factors most closely associated with whether or not a subject was absent, being absent from the checkup in 2011 was the most significant $\left(\mathrm{X}^{2}=11,078.2, \mathrm{df}=1, p<0.001\right)$ in two categories: (a) absent and (b) participated. Among subjects who participated in the checkup in 2011, those who had not undergone a medical examination for either hypertension or diabetes mellitus tended to participate in 2012 (absenteeism rate $=23.6 \%$ in Group A). 


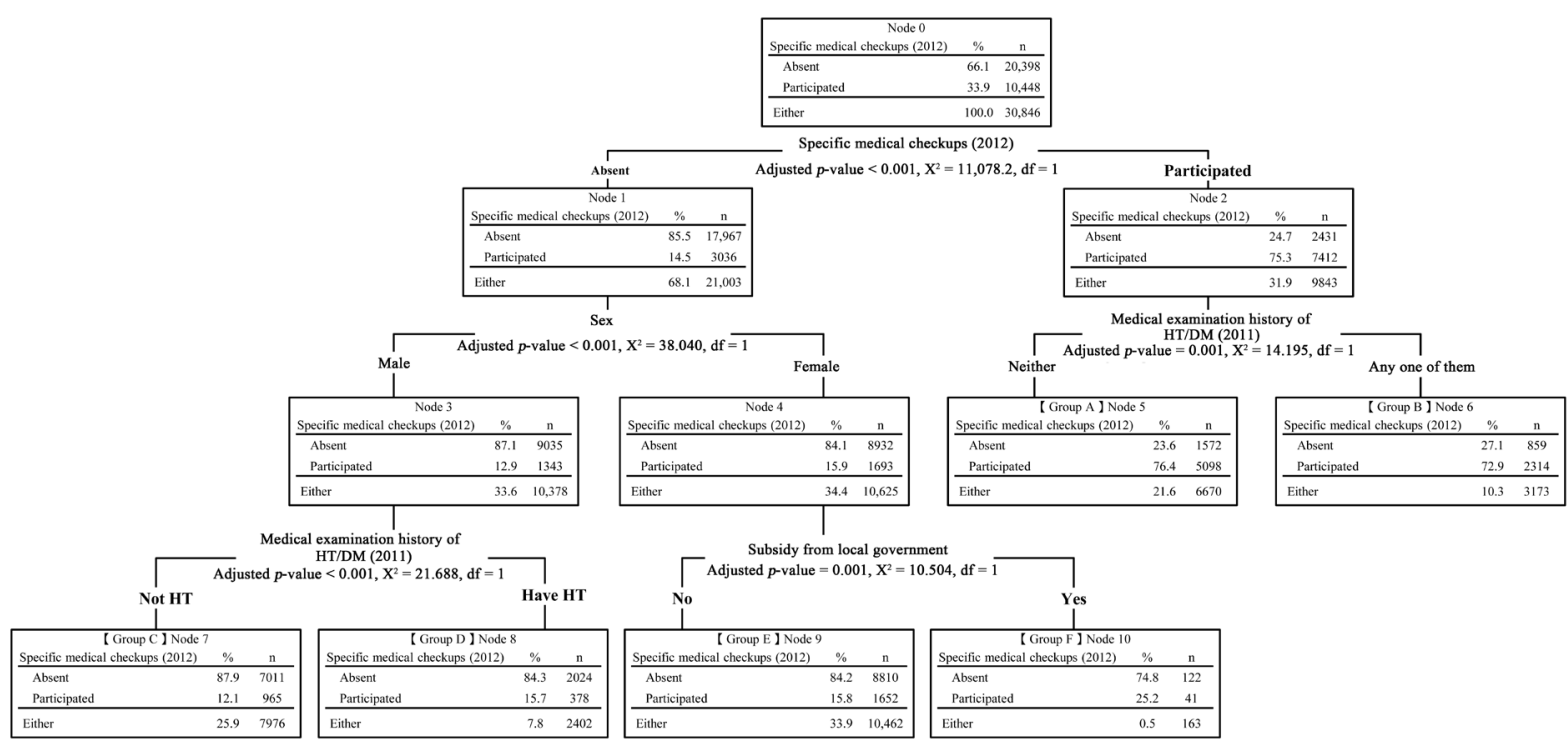

Figure 1. Dendrogram for participation in the specific medical checkup.

Table 1. Subject characteristics and participation in the specific medical checkup between April 2012 and March 2013.

\begin{tabular}{|c|c|c|c|c|c|c|}
\hline \multirow{3}{*}{ Variables } & \multirow{2}{*}{\multicolumn{2}{|c|}{ Total }} & \multicolumn{4}{|c|}{ Specific medical check up } \\
\hline & & & \multirow{2}{*}{\multicolumn{2}{|c|}{$\begin{array}{c}\text { Participated } \\
\text { n (\%) }\end{array}$}} & \multirow{2}{*}{\multicolumn{2}{|c|}{$\begin{array}{c}\text { Absent } \\
\mathrm{n}(\%)\end{array}$}} \\
\hline & $\mathrm{n}$ & (\%) & & & & \\
\hline \multicolumn{7}{|l|}{ Age (March 2011) } \\
\hline $60-69$ & 61,753 & & 20,831 & $(33.7)$ & 40,922 & $(66.3)$ \\
\hline \multicolumn{7}{|l|}{ Sex } \\
\hline Male & 28,626 & $(46.4)$ & 8471 & $(29.6)$ & 20,155 & $(70.4)$ \\
\hline Female & 33,127 & $(53.6)$ & 12,360 & $(37.3)$ & 20,767 & $(62.7)$ \\
\hline \multicolumn{7}{|c|}{ Examination for diabetes mellitus } \\
\hline Had undergone & 5130 & (8.3) & 1493 & $(29.1)$ & 3637 & $(70.9)$ \\
\hline No & 56,623 & $(91.7)$ & 19,338 & $(34.2)$ & 37,285 & $(65.8)$ \\
\hline \multicolumn{7}{|c|}{ Examination for Hypertension } \\
\hline Had undergone & 15,092 & $(24.4)$ & 5413 & $(35.9)$ & 9679 & $(64.1)$ \\
\hline No & 46,661 & $(75.6)$ & 15,418 & $(33.0)$ & 31,243 & $(67.0)$ \\
\hline \multicolumn{7}{|c|}{$\begin{array}{l}\text { Participation in the specific medical } \\
\text { checkup between April } 2011 \text { and March } 2012\end{array}$} \\
\hline Participated & 19,840 & $(32.1)$ & 14,886 & $(75.0)$ & 4954 & $(25.0)$ \\
\hline Absent & 41,913 & $(67.9)$ & 5945 & $(14.2)$ & 35,968 & (85.8) \\
\hline \multicolumn{7}{|c|}{ Subsidy from local government } \\
\hline Existance & 1365 & $(2.2)$ & 621 & $(45.5)$ & 744 & $(54.5)$ \\
\hline No & 60,388 & $(97.8)$ & 20,210 & $(33.5)$ & 40,178 & $(66.5)$ \\
\hline
\end{tabular}

Among subjects who were absent from the 2011 checkup, men (87.1\%, Node 3) tended to absent from the 2012 checkup compared to women (84.1\%, Node 4). Moreover, men without medical history of hypertension also tended to absent (87.9\%, Group C). The absenteeism rate among men with a hypertension examination was 84.3\% (Group D). Among women who lived in regions of municipalities without a free checkup program, absenteeism was 84.2\% (Group E). If women lived in municipalities with a free checkup program, the rate was 74.8\% (Group F).

Table 2 shows the prevalence of subjects who participated or were absent, data obtained using a developing tree model sample and a testing sample. The prevalence of absenteeism varied from $0.1 \%$ to $3.1 \%$ in each group. In both samples, the absenteeism rate was highest in Group C, followed by Groups D, E, F, B, and A. 
Table 2. Prevalence of subjects in dendrograms of learning sample and remaining testing sample.

\begin{tabular}{ccccccccccc}
\hline & \multicolumn{3}{c}{ Learning sample } & \multicolumn{3}{c}{ Remaining testing sample } \\
\cline { 2 - 9 } & \multicolumn{3}{c}{ Specific medical check up } & \multicolumn{3}{c}{ Specific medical check up } \\
\cline { 2 - 9 } & \multicolumn{2}{c}{ Participated } & \multicolumn{2}{c}{ Absent } & \multicolumn{2}{c}{ Participated } & Absent \\
\hline Group A & 5098 & $(76.4)$ & 1572 & $(23.6)$ & 5115 & $(75.7)$ & 1640 & $(24.3)$ \\
Group B & 2314 & $(72.9)$ & 859 & $(27.1)$ & 2359 & $(72.8)$ & 883 & $(27.2)$ \\
Group C & 965 & $(12.1)$ & 7011 & $(87.9)$ & 867 & $(11.0)$ & 7045 & $(89.0)$ \\
Group D & 378 & $(15.7)$ & 2024 & $(84.3)$ & 361 & $(15.2)$ & 2021 & $(84.8)$ \\
Group E & 1652 & $(15.8)$ & 8810 & $(84.2)$ & 1637 & $(15.7)$ & 8780 & $(84.3)$ \\
Group F & 41 & $(25.2)$ & 122 & $(74.8)$ & 44 & $(22.1)$ & 155 & $(77.9)$ \\
\hline
\end{tabular}

\section{Discussion}

\subsection{Proportion Absent from the Specific Medical Checkup}

Among the approximately 100,000 eligible adults, 29.6\% participated in the specific medical checkup between April 2012 and March 2013. This number is similar to the national trend in Japan, in which about $32.0 \%$ of the population insured by the National Health Insurance participated in the specific medical checkup in 2012 [7].

\subsection{Characteristics of Those Most Likely to Absent from the Specific Medical Checkup}

The dendrogram presents six groups of adults; the proportion of absent subjects ranged from $24.3 \%$ to $87.9 \%$. The primary predictor of being absent from the checkup was being absent from the same checkup in the previous year. In Groups A and B, in which subjects participated in the previous year's checkup, less than $28 \%$ of subjects were absent. In this case, the number was low enough that it has already met the stated goal of $30 \%$ [8].

In Groups C, D, and E, in which subjects were absent from the previous year's checkup, more than $84 \%$ of subjects were absent. In particular, the absenteeism rate of men without a medical history of hypertension (Group C) was quite high, with an $87.9 \%$ absenteeism rate. Accordingly, they were considered to be a high-risk population for being absent from the checkup.

Comparing Groups $\mathrm{C}$ and $\mathrm{E}$ indicates the impact of a free checkup program. Among women, the existence of a free checkup program decreased the absenteeism rate by $10 \%$. Because the total population of Group $\mathrm{E}$ was the largest, the effect of introducing free checkup programs on decreasing the total absenteeism rate in community adults might be large. This intervention for Group E was considered to be effective. Each municipality can estimate the cost-effectiveness of introducing a free checkup program through monitoring of women who were absent from the previous year's checkup.

\subsection{Limitations}

Because there was only one municipality that conducted a free checkup program, our results could not distinguish the positive effect of free checkup programs in conjunction with other municipality characteristics. Further, the data were obtained from one prefecture, thus we cannot apply the findings to other Japanese regions or other countries.

\section{Conclusion}

In conclusion, we found populations at higher risk of being absent from the specific medical checkup, including men, those who were absent from the previous year's checkup, and those with no history of hypertension. Our findings may help public health professionals determine those populations in need of intervention and to place them in order of precedence to effectively and efficiently improve the participation rate in the specific medical checkup. 


\section{Acknowledgements}

Financial support for this study was provided by the Health Labor Sciences Research program in 2013 and 2014 and a Grant-in-Aid for Scientific Research (KAKENHI; Japan) in 2013. Professor Yasushi Iwamoto of the University of Tokyo was the chief of the study team for the claim data analysis, Fukui Gerontology Study. Associate Professor Ryoko Morozumi of the University of Toyama and Associate Professor Michio Yuda of Chukyo University were board members of the Fukui Gerontology Study. They contributed to the claim data collection in this study. The authors would like to thank the staff of Fukui prefecture and the Institute of Gerontology at the University of Tokyo for their assistance in carrying out this research project.

\section{References}

[1] Koren-Morag, N., Goldbourt, U. and Tanne, D. (2005) Relation between the Metabolic Syndrome and Ischemic Stroke or Transient Ischemic Attack: A Prospective Cohort Study in Patients with Atherosclerotic Cardiovascular Disease. Stroke, 36, 1366-1371. http://dx.doi.org/10.1161/01.STR.0000169945.75911.33

[2] Ministry of Health, Labour and Welfare (2010) The National Health and Nutrition Survey Japan, Daiichi-Shuppan.

[3] Ministry of Health, Labour and Welfare (2014) Trend of Health and Medical Issue, in Health in Japan : Recent Vital Statistics, 2014/2015, Tokyo, Japan. Health, Labour and Welfare Statistics Association, 95-110.

[4] Nakano, K., Yabe, J. and Yasumura, S. (2006) Kihonkenkoshinsa Mijushin no koreisha niokeru seimeiyogoeno risukuyoin no kento. [An Investigation of Risk Factors in Vital Prognosis of Nonparticipants Older Ages in Basic Medical Examination.] Index of the Public Welfare, 53, 26-32.

[5] Ikeda, A., Iso, H., Toyoshima, H., Fujino, Y., Mizoue, T., Yoshimura, T., Inaba, Y. and Tamakoshi, A. (2005) The Relationships between Interest for and Participation in Health Screening and Risk of Mortality: The Japan Collaborative Cohort Study. Preventive Medicine, 41, 767-771. http://dx.doi.org/10.1016/j.ypmed.2005.07.007

[6] Health, Labour and Welfare Statistics Association (2014) Health Insurance and Long-Term Care Insurance, in Health in Japan: Recent Vital Statistics. 2014/2015, Tokyo, Japan. Health, Labour and Welfare Statistics Association, 234-297.

[7] All-Japan Federation of National Health Insurance Organizations (2012) Tokuteikenkoshinsa, tokutei-hokenshido jisshijoukyogaikyou houkokusho. [A Report on Implemenation Status of Specific Medical Checkup and Specific Health Guidance, Tokyo, Japan.]

[8] Health Insuranse Bureau General Administration Division, and Rationalization of Medical Expenses Measures Promotion Room (2012) Dainiki tokuteikenkoshisanado jisshikeikaku niokeru hokenjano mokuhyonitsuite. [About an Aim of Insurer in Implementation Plan of Specific Medical Checkup, Second Term.]

[9] Harlow, K.S. and Turner, M.J. (1993) State Units and Convergence Models: Needs Assessment Revisited. GeronTologist, 33, 190-199. http://dx.doi.org/10.1093/geront/33.2.190

[10] Ministry of Health, Labour and Welfare (2012) Ministerial Notification No. 430 of the Ministry of Health, Labour and Welfare. http://www.mhlw.go.jp/file/06-Seisakujouhou-10900000-Kenkoukyoku/0000047330.pdf

[11] Funahashi, H., Tomoko, N., Yukiko, O. and Hisataka, S. (2013) Attributes of Non-Participants Aged 40-59 Years in Specific Health Check-Ups. Japanese Journal of Public Health, 60, 119-127.

[12] Tsukishima, E., Takahashi, K., Yano, K. and Mori, M. (2012) Differences in Factors Associated with Health Checkup Participation between Persons with Differing Income Levels. A Cross-Sectional Analysis Using Residential Taxation as a Measure of Household Income. Japanese Journal of Public Health, 59, 810-821.

[13] Rygielski, C., Wang, J.C. and Yen, D.C. (2002) Data Mining Techniques for Customer Relationship Management. Technology in Science, 24, 483-502. http://dx.doi.org/10.1016/s0160-791x(02)00038-6

[14] Naruse, T., Nagata, S., Taguchi, A. and Murashima, S. (2010) Classification Tree Model Identifies Home-Based Service Needs of Japanese Long-Term Care Insurance Consumers. Public Health Nursing, 28, 223-232. http://dx.doi.org/10.1111/j.1525-1446.2010.00915.x 